\title{
Physical properties of extruded aquafeed with a combination of sago and tapioca starches at different moisture contents
}

\begin{abstract}
This study was conducted to determine the effects of sagoï tapioca starch ratio and moisture level of feed mixture on the physical properties of a Malaysian mahseer (Tor tambroides) extruded diet. Fifteen iso-nitrogenous diets containing varying ratios of sagoï tapioca starch (20:0, 15:5, 10:10, 5:15 and 0:20) and varying moisture contents $(200,300$, and $400 \mathrm{~g} / \mathrm{kg})$ were formulated. The feed mixtures were extruded using a single-screw extruder. The barrel temperature profile was set at $8010100 і 120{ }^{\circ} \mathrm{C}$ while the die temperature was set at $160{ }^{\circ} \mathrm{C}$. The physical properties of extruded diets (bulk density, expansion rate, floatability, water stability, pellet durability index, sinking velocity and scanning electron microscopy) were investigated. The results showed that increasing moisture level of diet from $200 \mathrm{~g} / \mathrm{kg}$ to 400 $\mathrm{g} / \mathrm{kg}$ increased $(\mathrm{P}<0.05)$ the value of all physical properties examined. The best moisture level to produce best floating extrudates using sago or tapioca or their combination was 400 $\mathrm{g} / \mathrm{kg}$. Sago starch and combinations of the sagoï tapioca starch performed as good as tapioca starch alone.
\end{abstract}

Keyword: Aquafeed; Extrusion; Sago; Starch; Tapioca 